COLUMBIA LAW REVIEW SIDEBAR

VOL. 115

APRIL 21, 2015

PAGES 79-92

\title{
JUDGES ON DEMAND: \\ THE COGNITIVE CASE FOR CAMERAS \\ IN THE COURTROOM
}

\author{
Jordan M. Singer*
}

In 2011, the federal district courts began a pilot program to record and post full-length videos from selected civil proceedings. The program was deliberately structured to preserve the quality and integrity of ongoing adjudication. Three-and-a-half years in, the program has revealed an equally important, and unanticipated, benefit: improving the quality and integrity of future adjudication. This Essay describes this second benefit and explains why the pilot program should be extended beyond its scheduled sunset in July 2015.

\section{INTRODUCTION}

For the past three-and-a-half years, fourteen federal district courts have quietly posted hundreds of hours of digital video to the Internet for public viewing. ${ }^{1}$ These videos, authorized by the Judicial Conference of the United States as part of a federal "Cameras in Courts" pilot program, cover an extensive range of full-length civil proceedings, from status conferences to multi-day trials. ${ }^{2}$ To date, more than 135 proceedings have been added to a growing video library, representing activity before dozens of different judges. Collectively, the videos have been viewed hundreds of thousands of times. ${ }^{3}$

The pilot program has emerged as an extraordinary resource for federal adjudication, providing a modern window into the courthouse for busy lawyers, anxious litigants, and a curious public. Ready access to recorded proceedings enables attorneys to familiarize themselves with

* Associate Professor of Law, New England Law | Boston. The author is grateful to Abel Mattos for invaluable background and feedback in preparing this piece, and to Elizabeth Bloom, Lawrence Friedman, Rebecca Katsh-Singer, and the editors of the Columbia Law Review for helpful comments on previous drafts.

1. See Cameras in Courts, U.S. Courts, http://www.uscourts.gov/Multimedia/ cameras.aspx [hereinafter U.S. Courts, Cameras in Courts] (on file with the Columbia Law Review) (last visited Apr. 2, 2015) (listing videos).

2. See id. (listing range of proceedings available under "Procedural Posture" tab).

3. Admin. Office of the U.S. Courts, 2013 Annual Report of the Director, Ongoing Pilots and Projects, available at http://www.uscourts.gov/FederalCourts/ UnderstandingtheFederalCourts/AdministrativeOffice/DirectorAnnualReport/annualreport-2013/the-courts/ongoing-pilots-projects-and-reports.aspx (on file with the Columbia Law Review). 
the culture of a particular courtroom and the personality of a particular judge, and allows litigants and prospective witnesses to familiarize themselves with the nature and flow of courtroom activity. Put another way, videotaped proceedings trigger a variety of cognitive processes in the viewer that cannot be duplicated by consulting standard written materials or secondhand information. The Judicial Conference should welcome this development, and should seize the opportunity to extend and expand the pilot program beyond its scheduled sunset date in July 2015.

Whether the Conference will do so is another matter. Neither the Chief Justice's 2014 Year-End Report on the Judiciary-which focused specifically on the use of technology in the federal courts ${ }^{4}$-nor the most recent Annual Report of the Director of the Administrative Office of the U.S. Courts (AO) ${ }^{5}$ saw fit to mention the pilot program at all. And the Judicial Conference itself has never publicly identified or discussed the cognitive benefits of video. Rather, the debate over cameras in federal courtrooms has consistently centered on the perceived threats that video cameras pose to the integrity of ongoing litigation-a concern that doomed the last federal attempt to record civil matters in the 1990s. ${ }^{6}$

Recognizing that this pilot program is different, and that video has the power to improve the quality of future proceedings, will require a reframing of the traditional conversation. This Essay begins that effort. It briefly traces the history of the "cameras in the courtroom" discussion in the federal courts and explains how the current pilot program differs in important ways from its 1990s-era predecessor. It then describes the variety of cognitive and educational benefits that accrue to future courtroom participants from viewing full-length videotaped proceedings. Finally, it offers some thoughts on how the Judicial Conference might beneficially expand the pilot program and make it permanent in the coming years.

\section{CAMERAS IN THE COURTROOM-THEN AND NOW}

The debate over the use of cameras in federal courtrooms dates to the dawn of the television era. In 1946, newly adopted Federal Rule of

4. See Chief Justice John G. Roberts, Jr., 2014 Year-End Report on the Federal Judiciary (Dec. 31, 2014), available at http://www.supremecourt.gov/publicinfo/yearend/2014year-endreport.pdf (on file with the Columbia Law Review).

5. See Admin. Office of the U.S. Courts, 2014 Annual Report of the Director, http://www.uscourts.gov/FederalCourts/UnderstandingtheFederalCourts/

AdministrativeOffice/DirectorAnnualReport/annual-report-2014.aspx (on file with the Columbia Law Review) (last visited Apr. 2, 2015).

6. See infra Part I (discussing 1990s attempt to introduce cameras in courtrooms); see also Sunshine in Courtroom Act of 2013: Hearing on H.R. 917 Before the Subcomm. on Courts, Intell. Prop. and the Internet of the H. Comm. on the Judiciary, 113th Cong. 21-22 (2014) (statement of Hon. Julie A. Robinson, Judge, U.S. Dist. Ct. for the Dist. of Kan.) (summarizing Judicial Conference's position on perceived dangers of courtroom cameras). 
Criminal Procedure 53 prohibited the "taking of photographs in the courtroom during judicial proceedings or the broadcasting of judicial proceedings from the courtroom." 7 The Judicial Conference doubled down in 1972, adding a clause to the Code of Conduct for United States Judges prohibiting "broadcasting, televising, recording, or taking photographs in the courtroom and areas immediately adjacent thereto" in both criminal and civil proceedings. ${ }^{8}$ Even after the U.S. Supreme Court affirmed the right of media access to state criminal trials in $1980,{ }^{9}$ another decade would pass before the federal courts opened to the idea of lifting their own recording restrictions.

The first formal attempt to introduce cameras occurred in September 1990, when the Judicial Conference adopted the report of its Ad Hoc Committee on Cameras in the Courtroom. ${ }^{10}$ That report struck the 1972 prohibition in the Code of Conduct and recommended a pilot program permitting electronic media coverage of civil proceedings. ${ }^{11}$ The pilot program ran in six district courts and two appellate courts between 1991 and 1994, and allowed media representatives to apply to a participating court for permission to cover all or part of a selected civil proceeding. ${ }^{12}$

By most contemporaneous accounts, the pilot program went well. A comprehensive Federal Judicial Center (FJC) study in 1994 found that the majority of courtroom participants did not perceive cameras to have adverse effects. ${ }^{13}$ To the contrary, district judges "believed electronic coverage had only minor effects on the participants or proceedings." ${ }^{14}$ Participating lawyers similarly indicated the belief that the presence of cameras had little or no effect on participants' behaviors or the overall fair-

\section{Fed. R. Crim. P. 53.}

8. Code of Conduct for United States Judges, Canon 3A(7) (1972).

9. Richmond Newspapers, Inc. v. Virginia, 448 U.S. 555, 556 (1980).

10. See Report of the Proceedings of the Judicial Conference of the United States 103-04 (Sept. 12, 1990), available at http://www.uscourts.gov/FederalCourts/Judicial Conference/Proceedings/Proceedings.aspx?doc=/uscourts/FederalCourts/judconf/proc eedings/1990-09.pdf (on file with the Columbia Law Review) (noting Ad Hoc Committee's belief that "controlled experimentation on a voluntary basis would offer federal judges the opportunity to observe first-hand the effect of camera coverage and broadcasting of proceedings in federal court").

11. See id. at 104 (advising use of cameras for any purpose during "ceremonial proceedings" and for security and other judicial administration purposes in "non-ceremonial proceedings").

12. Molly Treadway Johnson \& Carol Krafka, Fed. Jud. Ctr., Electronic Media Coverage of Federal Civil Proceedings: An Evaluation of the Pilot Program in Six District Courts and Two Courts of Appeals 1 (1994), available at https://bulk.resource.org/ courts.gov/fjc/elecmediacov.pdf (on file with the Columbia Law Review).

13. Id. at 7 ("Overall, attitudes of judges toward electronic media coverage of civil proceedings were initially neutral and became more favorable after experience under the pilot program.").

14. Id. at 12. 
ness of the proceedings. ${ }^{15}$ The FJC also reviewed studies on the impact of the electronic media in twelve state courts, and concluded that the presence of cameras was not distracting or anxiety-inducing to witnesses, and did not influence juror deliberations or outcomes. ${ }^{16}$

Acting on the FJC's conclusions, the Judicial Conference's Committee on Court Administration and Case Management (CACM) subsequently issued a recommendation to authorize photographing, recording, and broadcasting of civil proceedings in all federal district and appellate courts. ${ }^{17}$ But that recommendation went no further. In September 1994, the full Judicial Conference rejected the CACM proposal. ${ }^{18}$ Notwithstanding the FJC's findings to the contrary, the Conference explained that a majority of its members were concerned about the potentially intimidating effect of cameras on witnesses and jurors. ${ }^{19}$ Even though in 1996 the Judicial Conference authorized each federal court of appeal to make its own determination about whether to allow broadcasting, photographing, and videotaping in the courts within its circuit, the Conference still urged each circuit judicial council to adopt orders prohibiting the use of cameras. ${ }^{20}$

More than ten years would pass before the Judicial Conference took up the topic of courtroom cameras again. In 2007, however, three separate events increased pressure on the Conference to revisit the issue. First, CACM recommended-and the Judicial Conference approved-a pilot program to allow judges to release audio recordings of court proceedings on PACER, the federal courts' online docket management portal. ${ }^{21}$ Second, the Ninth Circuit's Judicial Conference changed its internal policy to permit photos and recording in district courtrooms. ${ }^{22}$ Finally, members of the U.S. House of Representatives reintroduced the Sunshine in the Courtroom Act, a bipartisan bill to place cameras in

15. Id. at 22 .

16. Id. at 39-41.

17. Report of the Proceedings of the Judicial Conference of the United States 46-47 (Sept. 20, 1994), available at http://www.uscourts.gov/FederalCourts/Judicial Conference/Proceedings/Proceedings.aspx?doc=/uscourts/FederalCourts/judconf/proc eedings/1994-09.pdf (on file with the Columbia Law Review).

18. Id. at 46-47, 67 (" $[\mathrm{T}]$ he Conference concluded that the intimidating effect of cameras on some witnesses and jurors was cause for concern, and ... declined to approve the Committee's recommendation to expand camera coverage in civil proceedings.").

19. Id. at 47.

20. Report of the Proceedings of the Judicial Conference of the United States 17 (Mar. 12, 1996), available at http://www.uscourts.gov/FederalCourts/Judicial Conference/Proceedings/Proceedings.aspx?doc=/uscourts/FederalCourts/judconf/proc eedings/1994-09.pdf (on file with the Columbia Law Review).

21. Pilot Project Will Post Digital Audio Recordings Online, The Third Branch (June 2007), http://www.uscourts.gov/news/TheThirdBranch/07-06-01/Pilot_Project_Will_Post _Digital_Audio_Recordings_Online.aspx (on file with the Columbia Law Review).

22. The Ninth Circuit has requested formal approval for this change from the Judicial Conference of the United States, which remains pending as of this writing. 
federal courthouses. ${ }^{23}$ While the Judicial Conference did not react immediately to this final development, Congress's ongoing interest in courtroom video must have suggested to CACM and the Judicial Conference the value of an internally developed cameras program.

Pressure for an internal solution grew in 2009, when U.S. District Judge Nancy Gertner granted a motion to "narrowcast" a non-evidentiary motion hearing in a high-profile music piracy case in Boston. The proposed narrowcast would send video of the proceeding to a secure website operated by the Berkman Center at Harvard Law School, which in turn would allow the public to access the recordings. ${ }^{24}$ On appeal, the First Circuit held that the narrowcast was impermissible in light of existing Judicial Conference policy, corresponding First Circuit policy, and the relevant District of Massachusetts Local Rule. ${ }^{25}$ But the ongoing advisability of those policies was another matter. Concurring, Judge Kermit Lipez wrote that while the existing rules mandated the court's decision, "there are no sound policy reasons to prohibit the webcasting authorized by the district court. Therefore, this case calls into question the continued relevance and vitality of a rule that requires such a disagreeable outcome." ${ }^{26}$ The developments in the Ninth and First Circuits suggested that if the Judicial Conference did not act on its own to reintroduce cameras, the regional circuit judicial conferences might lead the way.

By the end of the decade, then, the Judicial Conference found itself in a difficult position. Members of Congress, as well as some lower court judges, were publicly advocating for the implementation of courtroom video. At the same time, the majority of Judicial Conference members remained deeply concerned that "broadcasting ... court proceedings could have an intimidating effect on litigants, witnesses, and jurors," that "some participants in the proceedings might grandstand, and that the prospect of televising could also be used as a negotiating tactic in pretrial settlement discussions." 27 Put another way, the Judicial Conference worried that the immediacy of the news cycle and the high-profile nature of certain cases would converge to corrupt the integrity of ongoing court proceedings. Any new cameras program would have to advance the cause of transparency while simultaneously minimizing these perceived risks.

23. H.R. 2128, 110th Cong. (2007). The original bill had been introduced in the Senate two years earlier. S. 829, 109th Cong. (2005). Similar legislation had been introduced consistently in both houses of Congress since the 105th Congress. For a brief but detailed history, see Lorraine H. Tong, Cong. Research Serv., RL33706, Televising Supreme Court and Other Federal Court Proceedings: Legislation and Issues 6-10 (2006).

24. See Capitol Records, Inc. v. Alaujan, 593 F. Supp. 2d 319, 321, 323 (D. Mass. 2009) (noting Berkman Center would not edit video footage "in any way").

25. See In re Sony BMG Music Entm't, 564 F.3d 1, 5-9 (1st Cir. 2009).

26. Id. at 11 (Lipez, J., concurring).

27. See Tong, supra note 23, at 6 (quoting 2006 letter from Director of AO to thenSenate Judiciary Committee Chairman Arlen Specter stating Conference's strong opposition to "cameras in the courtroom" legislation). 
It was within this context, and with these goals, that the Judicial Conference authorized the current pilot program in September 2010. The pilot program bears some facial similarities to its 1990s-era predecessor: volunteer districts (fourteen this time) were selected by CACM to participate, and recording is limited to civil proceedings only. ${ }^{28}$ No proceedings may be recorded without the approval of the presiding judge and the consent of the parties, and no district court other than those selected for the pilot program may record proceedings for the purpose of public release. As before, the FJC has been charged with monitoring and reviewing the pilot program.

This time, however, there is also a critical difference: the broadcast media has no involvement. The courts run the program themselves and maintain complete control over the cameras and resulting videos. All recordings must be undertaken by a court employee or a private contractor controlled by the court, and the equipment must meet guidelines developed by the $\mathrm{AO}$. By rule, jurors are off-limits, as are conversations between attorneys and their clients, non-public discussions among attorneys, and sidebar conversations between attorneys and the judge. The presiding judge also has wide latitude to limit or terminate the recording of any portion of a case or hearing. ${ }^{29}$ Once posted, each video is accompanied by a detailed summary of the case, with a list of pertinent docket entries and a link to the case's PACER docket.

Whatever First Amendment and public interest issues the broadcast media's exclusion might raise, the intent of the current pilot program's structure is clear. Eliminating the immediacy of the television news cycle addresses the Judicial Conference's previously stated concerns about protecting the integrity of ongoing litigation. Posting uncut proceedings, accompanied by meaningful information about the case, responds to fears that events depicted in the videos will be taken out of context. And focusing on typical cases, rather than those that draw unusual media attention, aims to soothe concerns that the administration of justice will be caricatured in the mind of the public.

\section{THE AUdiEnCE OF FUtURE COURTROOM PARTICIPANTS}

The pilot program was designed to neutralize the perceived harms of courtroom cameras to ongoing proceedings. But the same design has

28. This limitation reflects the ongoing prohibition on recording criminal proceedings. See Fed. R. Crim. P. 53.

29. Presiding judges may limit or terminate recording "in the interests of justice; to protect the rights of the parties, and witnesses, and the dignity of the court; to assure the orderly conduct of proceedings; or for any reason considered necessary or appropriate by the presiding judge." Judicial Conference Committee on Court Administration and Case Management Guidelines for the Cameras Pilot Project in the District Courts, Guideline 4.a., available at http://www.uscourts.gov/uscourts/News/2011/docs/Cameras Guidelines.pdf (on file with the Columbia Law Review). 
unexpectedly unearthed a remarkable benefit of courtroom video: the ability of future court users to learn about the procedures, personalities, and relationships that govern courtroom interactions. While videos lack the precedential value of written opinions and the relative predictability of court rules and standing orders, they nevertheless carry the same ability to establish expectations among those who will interact with the court at a later date. From both an educational and a cognitive perspective, they provide a valuable resource for those who would bring their disputes into the federal system.

\section{A. The Benefits of Direct Courtroom Observation}

To understand the power of video observation, one must first consider the power of observation generally. Even in an era of big data and natural language searches, taking in live courtroom proceedings continues to offer distinct advantages to lawyers and litigants. In particular, watching legal actors at work provides four cognitive benefits for the observer: (1) education about the timing and procedural handling of litigation events; (2) acculturation to the tone, tenor, and mechanics of the courtroom; (3) the opportunity to judge the fairness of the court's procedures; and (4) the ability to form impressions about the judge and other courtroom actors.

Procedural education. New attorneys often have limited expectations and understanding about the specific flow and timing of courtroom proceedings. Law students and self-represented litigants have even less. It is one thing to understand that the court convenes pretrial conferences, permits the use of appropriate demonstratives to aid the factfinder, or addresses motions in limine on the eve of trial. It is another thing altogether to understand and anticipate the flow of argument, the introduction and use of evidence, or the issues the court is likely to emphasize. Watching more experienced lawyers at work in the courtroom (especially before the same judge) can provide an excellent baseline expectation and foster awareness of how events unfold in a particular court.

Attorney acculturation. Each court, and each courtroom, has its own culture and rhythm. For attorneys who are new to a court, grasping the local legal culture is as essential as mastering the relevant procedures and substantive arguments. ${ }^{30}$ The focus here is on the nature of the interaction between and among the various courtroom players. Is the judge's approach formal or conversational? How do opposing counsel treat each other? Are there unwritten expectations about how arguments will be presented, rules enforced, or objections raised? While conferring with experienced local counsel can provide some insight, only direct experience or observation fully answers these questions.

30. See generally Andrea M. Seielstad, Unwritten Laws and Customs, Local Legal Culture, and Clinical Legal Education, 6 Clinical L. Rev. 127 (1999) (elaborating on importance of advocates understanding local legal culture). 
Fairness judgments. Observing courtroom activity also contributes to perceptions about the court's commitment to procedural fairness, which in turn influences the judiciary's overall legitimacy in American society. Third-branch legitimacy is tied to perceptions that court procedures are participatory, impartial, trustworthy, and dignified. ${ }^{31}$ These qualities may be reflected in written orders and opinions, but they are much more readily observable during proceedings in the open courtroom. ${ }^{32}$ Litigants, attorneys, witnesses, and other interested parties form judgments about the soundness of the court's rulings based in significant part on their direct interaction with court officers, or by observing the direct interaction of others. These observations are particularly important for civil litigants, whose contact with the court is likely to be relatively limited, and whose time watching the judge and court staff at work is bound to leave a lasting impression.

Impression formation. In addition to providing information necessary to form fairness judgments, observing trials and hearings provides information necessary to form impressions of the judge and other courtroom actors. Whereas attorney acculturation considers courtroom actors as a cultural unit, impression formation considers those actors individually. For example, mental impressions of the presiding judge create expectations about the judge's likely tone, demeanor, and reactions to arguments and evidence. Lawyers use these impressions to anticipate judicial behavior and construct their presentations in the way most likely to resonate with the judge. ${ }^{33}$ Litigants and witnesses may tailor their testimony and courtroom tenor as well: Judges who are seen as patient, well-prepared, or strict will warrant a different approach at a hearing than judges who are seen as hurried, unprepared, or lenient, even when the underlying facts and applicable law are identical. Over time, continued observation or interaction with the judge will refine an impression of the judge's personality, ${ }^{34}$ leading to more confident approaches in the courtroom.

Live courtroom observation, then, carries a number of important benefits for those who will actively participate in civil litigation. Unfortunately, practical opportunities to undertake live observation are rapidly dwindling. For one thing, there is much less activity to observe than there

31. Tom R. Tyler, Social Justice: Outcome and Procedure, 35 Int'l J. Psychol. 117, 121 (2000).

32. See Hon. William G. Young \& Jordan M. Singer, Bench Presence: Toward a More Complete Model of Federal District Court Productivity, 118 Penn St. L. Rev. 55, 85-87 (2013) (describing procedural fairness benefits of open court proceedings).

33. For a detailed discussion of impression formation in litigation, see Jordan M. Singer, Gossiping About Judges, 42 Fla. St. U. L. Rev. 427, 438-50 (2015).

34. Perceptions of a person's agreeableness, conscientiousness, and emotional stability are particularly volatile and subject to change as new information comes in. See Lara K. Kammrath, Daniel R. Ames \& Abigail A. Scholer, Keeping Up Impressions: Inferential Rules for Impression Change Across the Big Five, 43 J. Experimental Soc. Psychol. 450, 452 (2007) (noting finding of volatility based on experimental study). 
was even five years ago. ${ }^{35}$ For another, modern billing pressure makes it all but impossible for attorneys to be mere spectators in the courthouse. Lawyers who are interested in learning about particular proceedings, particular courts, or particular judges must find ways to do so on their own time and in their own ways. The federal pilot program has once again made this sort of learning practical and accessible.

\section{B. The Benefits of Digital Video Observation}

The longstanding benefits of courtroom observation to attorneys, litigants, and witnesses translate well to digital video review. Ready access to video recordings of courtroom proceedings allows lawyers, litigants, and other interested observers to time- and place-shift their observation with relatively little cognitive drop-off. ${ }^{36}$ The posted videos also present educational benefits that are nearly identical to live courtroom viewing. Relatively inexperienced attorneys can watch videos covering a variety of case types, hearing types, and judge types, and in doing so can internalize both the dynamics of a hearing and the cultural expectations of attorneys and others in the courtroom. Similarly, law students can observe hearings in order to breathe life into the rules and cases they cover in class: Even the most garden variety summary judgment hearing is far more lively and memorable than a dry reading of Rule 56. Law professors may use appropriate videos to illustrate substantive legal concepts, procedural rules and strategies, and courtroom presentation.

Digital videos also offer important educational benefits for self-represented litigants and other participants who likely have limited exposure to the courtroom. The pro se litigant who expects simply to tell his story to a sympathetic judge is more likely to understand the formal nature of a typical courtroom hearing after watching a video. Indeed, several currently posted videos keenly illustrate many surprising formalities for the inexperienced self-represented litigant, including the need to address burdens of proof and overcome evidentiary hurdles, the realization that even a patient and kind judge will not act as counselor for an unrepresented party, and the regularity with which a judge will interrupt argument to clarify or focus discussion. ${ }^{37}$ While digital video is hardly a sub-

35. Courtroom hours in the federal district courts are in steady decline, down ten percent over the last six years. Jordan M. Singer \& Hon. William G. Young, Bench Presence 2014: An Updated Look at Federal District Court Productivity, 48 New Eng. L. Rev. 565, 566 (2014).

36. Put slightly differently, the cognitive benefits that accrue while observing videotaped courtroom proceedings can be nearly as effective as the benefits that accrue during live observation.

37. See, e.g., video of summary judgment hearing in Hammock v. Jensen, Case No. 3:12-cv-00094-CRW (S.D. Iowa), Hearing of Feb. 22, 2013, http://www.uscourts.gov/ Multimedia/Cameras/SouthernDistrictofIowa.aspx?video_uuid=u7o397yk\&categoryId=51 459 (on file with the Columbia Law Review) (showing, from 3:32 to 7:48 of video, a colloquy between court and pro se plaintiff featuring frequent interjections by judge to focus discussion on plaintiff's claim); video of motion to dismiss hearing in Lu v. Boston College, 
stitute for legal training, the time that a self-represented party spends educating him- or herself about courtroom proceedings through video can help align expectations with the reality of courtroom litigation, and improve the quality of presentation and argument.

The cognitive benefits of video would also seem to outweigh any potential drawbacks. The most significant concern is probably the so-called "thin slice" problem: A viewer may be tempted to watch just the first few minutes of a recorded proceeding, or skip ahead, or multitask while the video plays in the background-actions that may lead the viewer to develop distorted impressions of the proceeding and its participants. ${ }^{38}$ In the specific context of federal litigation, however, the dangers posed by thin-slice observation seem overstated. Litigators gain strategic advantage by understanding how best to present evidence and argument to the court, and therefore have a strong incentive to form correct impressions of the judges before whom they appear. Indeed, if the legal community's robust marketplace of secondhand information on judges is any indication, ${ }^{39}$ lawyers are already conditioned to devote significant time to forming careful impressions of judicial officers. Video simply provides another useful tool toward that end. ${ }^{40}$

Thin-slice concerns are also likely to be mitigated for non-attorney courtroom participants. For example, recent studies suggest that people who view video with a particular content goal in mind are more likely to watch for longer periods and to focus less on immediate personality impressions. ${ }^{41}$ Therefore, a law student or self-represented litigant who watches a video in order to better understand the flow of a motion

Case No. 12-cv-10326-WGY (D. Mass.), Hearing of Jan. 10, 2013, http:/ /www.uscourts.gov/ Multimedia/Cameras/DistrictofMassachusetts.aspx?video_uuid=te7p6rfh\&categoryId=497 31 (on file with the Columbia Law Review) (showing, at 0:40 to 2:45 of video, court attempting to frame issue for discussion after pro se plaintiff came unprepared to make a preliminary statement, and at 10:00 to 10:30 of the video, court gently advising plaintiff not to interrupt a colloquy between the judge and defense counsel).

38. For a brief summary of the extant literature on thin-slice impressions in social situations, see Daniel R. Ames et al., Not So Fast: The (Not Quite Complete) Dissociation Between Accuracy and Confidence in Thin-Slice Impressions, 36 Personality \& Soc. Psychol. Bull. 264, 264 (2010).

39. See Singer, supra note 33 , at 433-36 (identifying many ways in which attorneys share and obtain secondhand information on judges).

40. A somewhat related concern is that attorneys might canvass videos before filing a lawsuit in the hope of targeting a sympathetic judge. But randomized case assignments have already made judge-shopping in the federal district courts virtually impossible. See Frequently Asked Questions: Federal Judges, United States Courts, http:// www.uscourts.gov/Common/FAQS.aspx (on file with the Columbia Law Review) (noting "majority of [federal district] courts use some variation of a random drawing" to assign new cases).

41. See Kevin Miller \& Xiaobin Zhou, Learning from Classroom Video: What Makes It Compelling and What Makes It Hard, in Video Research in the Learning Sciences 321 (R. Goldman-Segal et al. eds., 2007) (describing study in which viewers with more substantive content goals focused less on personality impressions when watching videos than did viewers with fewer substantive content goals). 
hearing or to identify which substantive legal elements engender significant discussion should be inclined to watch longer and with greater focus on achieving that understanding.

A different form of the "thin slice" problem, which posits that the news media distorts public perception by airing only short, decontextualized segments of court proceedings, has motivated several Supreme Court Justices to oppose courtroom cameras altogether. ${ }^{42}$ The structure of the pilot program, however, directly safeguards against this form of intermediated distortion. As described above, the broadcast media have no access to raw courtroom footage, and may review video only through the U.S. Courts website in the same manner as the general public. Moreover, the events selected for recording reflect not the sensational and high-profile proceedings that drive news coverage, but rather the wealth of ordinary proceedings that make up the courts' everyday docket. ${ }^{43}$ In other words, both the timing and the content of the posted proceedings dampen the likelihood that they will be pulled for use on the nightly news. While the "thin slice" problem cannot be completely eliminated, the opportunities for distortion and mischief are far outweighed by the opportunities for improved adjudication and public understanding.

\section{EXTENDING AND EXPANDING THE CURRENT PROgRAM}

The cognitive and educational benefits of the current pilot program mesh seamlessly with the federal judiciary's own long-term strategies and objectives. The Judicial Conference's 2010 Strategic Plan for the Federal Judiciary, for example, calls for "[h]arness[ing] the potential of technology to identify and meet the needs of court users for information, service, and access to the courts." ${ }^{44}$ That plan also identifies the federal judiciary's goal of "provid[ing] jurors, litigants, witnesses, and observers with comprehensive, readily accessible information about court cases and the work of the courts." ${ }^{45}$ The pilot program goes a long way toward meeting

42. See, e.g., Role of Judges Under U.S. Constitution (C-SPAN television broadcast Oct. 5, 2011), available at https://www.youtube.com/watch?v=SWU0wpFMOsE (showing interview of Justices Scalia and Breyer in which they express opposition to recording Supreme Court sessions). Other Justices have articulated similar concerns in recent years. See Robert Kessler, Why Aren't Cameras Allowed at the Supreme Court Again?, Wire, http:/ /www.thewire.com/national/2013/03/case-allowing-cameras-supreme-courtproceedings/63633/ (Mar. 28, 2013, 8:39 AM) (on file with the Columbia Law Review) (quoting current Supreme Court Justices opinions on cameras in Supreme Court proceedings).

43. As one U.S. district judge has put it, at their core the videos depict "a work-a-day judge at work." Home page of Judge William G. Young, United States District Court for the District of Massachusetts, http://www.mad.uscourts.gov/boston/young.htm (last visited Mar. 10, 2015) (on file with the Columbia Law Review).

44. Judicial Conference of the U.S., Strategic Plan for the Federal Judiciary 11 (Sept. 2010).

45. Id. at 14 (Goal 5.2a). 
those objectives. Court users and the public may place themselves inside the courtroom at any time and from anywhere, armed with easy access to case information and a rich context for what they are observing.

Or at least they may for some courtrooms and some proceedings. With successful implementation underway in fourteen districts, ${ }^{46}$ the Judicial Conference should act now to make the program permanent and expand it to include every federal district court and every federal district judge. ${ }^{47}$

Such expansion should be deliberate, in both senses of the word: It should be intentional, and it should be cautious. While the final product should be a single website containing videos from every federal district court and every federal district judge, and reflecting a vast range of different court proceedings, it is obviously impractical to require the courts to generate such expansive material in the short term. Rather, CACM and the Judicial Conference should develop a strategic growth plan for the pilot program, with the goal of a comprehensive and resource-rich website that is continually updated with new videos and information.

The current pilot program already offers an excellent baseline with easy opportunities for further development. Case summaries already help situate the viewer; linking the video to relevant written materials and transcripts from the case (through PACER) would be a helpful next step. In an expanded pilot program, the current video index (which organizes proceedings by court, case type, and proceeding type) might also include a category for the presiding judge, and the ability to search case summaries. There are also substantial opportunities to tout an expanded pilot program. Currently, the U.S. Courts homepage only references the pilot program through a small box in the bottom left corner, ${ }^{48}$ perhaps reflecting the Conference's own ambivalence about the project. A largerscale publicity campaign targeted at attorneys, law schools, and pro se litigants would greatly increase viewership for an expanded program. Indeed, the demand is already there: Despite relatively limited publicity, more than 175,000 individual video views took place in the pilot program's first two years, and many law firms used the videos as training aids for junior lawyers. ${ }^{49}$ An expansion of the program should allow the courts to explore additional avenues to reach their target audiences.

46. See U.S. Courts, Cameras in Courts, supra note 1 (showing available videos from all fourteen pilot districts).

47. Why every district judge and every district court? Just as each lawsuit has its own history and nuances, each district judge has his or her own approach to adjudication. Including every judge in the video archives maximizes the program's benefits by allowing future court participants to prepare for interaction in any given courtroom and with any given judge.

48. U.S. Courts, http://www.uscourts.gov/Home.aspx (last visited Apr. 2, 2015) (on file with the Columbia Law Review).

49. Pat Nordell, The Jury Is Still Out on "Cameras in the Courtroom," Gov't Video (Jun. 14, 2013), http://www.governmentvideo.com/article/the-jury-is-still-out-on-\%E2\% 
Aggressive promotion of an expanded program would also serve as an excellent bulwark against the residual dangers of "thin slice" reporting. The courts are already well-positioned to combat such distortion by making complete videos available to the public, and providing rich contextual background for each video- the very tools currently employed by the pilot program. A detailed video library, optimized for commercial search engines and widely promoted to the public at large, would give the federal courts a significant voice as to when and how the public views their proceedings.

Expansion, of course, also raises the perennial issue of cost and administrative burden on court staff-one to be taken seriously given the federal courts' limited resources. Someone has to set up cameras, ensure proper recording and editing, and post the videos with background information. To date, the pilot program courts have relied on their own IT staff, and have required lawyers to remain standing before a fixed microphone in order to capture their voices and images properly. ${ }^{50}$ An expanded program would require a cadre of well-trained staff to service every district court, and ideally would take advantage of portable microphones and easily manipulated video cameras to allow attorneys to move more freely during recorded proceedings. Ample technology already exists, ${ }^{51}$ but resources may be required for training and operation. Still, careful and deliberate expansion can effectively allocate those resources. Not every proceeding need be taped, and technical resources can be shared and moved among district courts.

This is ultimately a modest proposal, focused exclusively on extending the benefits of the pilot program to all federal district court users. Should the Judicial Conference seek a more ambitious expansion, however, the lessons of the pilot program can also be usefully (if tentatively) extrapolated to other video settings. For example, the cognitive benefits of digital video observation would appear to apply equally well to appellate proceedings. Attorneys viewing oral arguments on video likely will be better positioned to anticipate the ebb and flow of a hearing, assess the collective tone and tenor of an appellate panel, and predict the approaches of individual judges than will attorneys who have not undertaken similar observation. The advantages of video observation also trans-

$80 \% 98$ cameras-in-the-courtroom $\%$ E2\%80\%99/114537 (on file with the Columbia Law Review).

50. Id.

51. Id. As the federal courts have already recognized, tablet computers may provide an excellent and relatively inexpensive alternative, as they have undergone significant improvements in recording quality in recent years, and can be put to other use in the courthouse when not recording proceedings. See Admin. Office of the U.S. Courts, 2014 Annual Report of the Director, Innovations, http://www.uscourts.gov/FederalCourts/ UnderstandingtheFederalCourts/AdministrativeOffice/DirectorAnnualReport/annualreport-2014/innovations.aspx (on file with the Columbia Law Review) ("The AO's video production team is partnering with courts to help them use smartphones and tablets to produce their own low-cost educational and outreach videos."). 
late well to live-streaming, offering the same cognitive advantages of procedural education, attorney acculturation, fairness judgments, and impression formation to live-stream observers as they do to viewers of archived video.

Whether these benefits can outweigh other challenges associated with broader implementation remains to be seen. But the benefits themselves are plain. Indeed, the primary lesson of the pilot program may be that video technology can provide long-term gains for quality adjudication and public understanding that are entirely separate from the decades-old debate over media access to the courtroom. The federal courts have opened their doors to the public for more than two hundred years. Videotaped arguments are a natural, twenty-first century extension of that tradition.

\section{CONCLUSION}

With relatively little fanfare, CACM and the Judicial Conference have developed a unique resource for improving the quality of federal adjudication. Access to a video library of diverse civil proceedings allows future court participants-be they lawyers, litigants, witnesses, or jurorsto better understand and anticipate the nature of federal district court activity. In particular, videotape observation facilitates procedural education, exposes attorneys to the culture of a particular courtroom, permits parties to make informed fairness judgments, and generates mental impressions of the judge and other courtroom actors. As an added bonus, the pilot program profitably refocuses public attention from the unusual and sensational cases to the routine and important work the courts do every day. Judges and court users alike should delight in the pilot program's initial success and ongoing promise. Extending and thoughtfully expanding the pilot program to all federal district courts is the logical next step.

Preferred Citation: Jordan M. Singer, Judges on Demand: The Cognitive Case for Cameras in the Courtroom, 115 COLUM. L. REV. SIDEBAR 79 (2015), http://www.columbialawreview.org/Cognitive_Singer 